\title{
Pulmonary eosinophilia with and without allergic bronchopulmonary aspergillosis
}

\author{
B J CHAPMAN, S CAPEWELL, R GIBSON, A P GREENING, G K CROMPTON \\ From the Respiratory Unit, Northern General Hospital, Edinburgh
}

ABSTRACT Sixty five patients with pulmonary eosinophilia attending one respiratory unit were reviewed. All had fleeting radiographic abnormalities and peripheral blood eosinophil counts greater than $500 \times 10^{6} / 1$. Eighteen had a single episode and 47 recurrent episodes during a median follow up period of 14 years. Thirty three patients had allergic bronchopulmonary aspergillosis on the basis of a positive skin test response to Aspergillus fumigatus, serum precipitins, or culture of $A$ fumigatus from sputum, or a combination of these. All but seven patients had asthma, six of the seven being in the group who did not have allergic bronchopulmonary aspergillosis. The patients with allergic bronchopulmonary aspergillosis were more often male and had a greater incidence of asthma and an earlier age of onset of asthma than those without aspergillosis. The patients with aspergillosis had lower mean blood eosinophil counts and more episodes of pulmonary eosinophilia and more commonly had radiographic shadowing that suggested fibrosis or bronchiectasis $(20 v 7)$. Pulmonary eosinophilia associated with allergic bronchopulmonary aspergillosis appears to be a distinct clinical syndrome resulting in greater permanent radiographic abnormality despite lower peripheral blood eosinophil counts.

\section{Introduction}

The term pulmonary eosinophilia describes a group of disorders in which transient radiographic lung shadows are associated with a raised blood eosinophil count. ${ }^{1}$ Allergic bronchopulmonary aspergillosis is the most common cause of pulmonary eosinophilia in Britain. $^{23}$ Pulmonary eosinophilia has also been described in association with other fungi, ${ }^{4}$ an increasing number of drugs, ${ }^{5}$ the systemic vasculitides, ${ }^{67}$ and the hypereosinophilic syndrome. ${ }^{89}$ Most cases of tropical pulmonary eosinophilia are allergic reactions to filarial infestations, ${ }^{10}$ whereas various helminths have been implicated in more temperate latitudes. " About $20 \%$ of cases of pulmonary eosinophilia in Britain are unexplained and labelled cryptogenic. ${ }^{1213}$ Recommended classifications have their limitations, whether based on clinical features, ${ }^{14}$ aetiology, ${ }^{11} 15$ or anatomical and pathological features. ${ }^{17}$

There are many published studies on allergic bronchopulmonary aspergillosis, but fewer on pulmonary eosinophilia. ${ }^{312}$ Most studies have origin-

Address for reprint requests: Dr G K Crompton, Respiratory Unit, Northern General Hospital, Edinburgh, EH5 2DQ.

Accepted 14 August 1989 ated from secondary and tertiary referral centres, which makes it difficult to estimate the relative frequency of the various underlying conditions. The differences between patients with and without allergic bronchopulmonary aspergillosis are not clear. We therefore reviewed an unselected series of patients with pulmonary eosinophilia attending a primary referral unit during a 20 year period.

\section{Methods}

Sixty five patients with pulmonary eosinophilia attending the Northern General Hospital, Edinburgh, during 1966-86 were identified. All had evidence of transient pulmonary shadowing associated with a peripheral blood eosinophil count exceeding $500 \times 10^{6} / 1$. The patients' medical records were reviewed for evidence of asthma, atopy, hypersensitivity to Aspergillus fumigatus, clinical features associated with episodes of pulmonary eosinophilia, pulmonary function tests, corticosteroid treatment, radiographic features, and possible aetiological factors other than $A$ fumigatus. Patients with aspergilloma were excluded.

Patients were considered to be asthmatic if there was evidence of airflow obstruction (FEV $1<70 \%$ predicted) and more than $15 \%$ variation in $\mathrm{FEV}_{1}$ over 
a short period either spontaneously or in response to bronchodilator treatment. Atopy was defined by two or more positive skinprick test responses to common allergens (grass pollens, shrubs, tree mix, house dust, house dust mites, feathers, dog hair, and cat fur), excluding Aspergillus species (Bencard). A fumigatus precipitins were identified by an Agar-gel double diffusion technique using $A$ fumigatus antigens 1 and 11 (Bencard). A diagnosis of allergic bronchopulmonary aspergillosis was made if an immediate skinprick test'response to $A$ fumigatus was positive, and if serum precipitins to $A$ fumigatus were present or A fumigatus was cultured from sputum. Bronchiectasis was identified by bronchography (nine patients) or by radiographic shadowing that suggested fibrosis or bronchiectasis with (five) or without (13) a history of chronic cough and sputum.

The results were analysed by the $\chi^{2}$ test with Yates's correction and Wilcoxon's rank sum test for unpaired data. ${ }^{18}$

\section{Results}

Sixty five patients ( 27 male, 38 female) were identified. There were 247 recorded episodes of pulmonary eosinophilia, 18 patients having single and 47 patients recurrent episodes. The median age at the time of the first episode was 39 (range 12-78) years and the median follow up period 14 (range 1-31) years.

Thirty three patients met the criteria for allergic bronchopulmonary aspergillosis (table 1). The remaining 32 were labelled "non-allergic bronchopulmonary aspergillosis." Eight of the 32 had an isolated positive skin test response to $A$ fumigatus (table 2). There was no evidence of drug induced pulmonary eosinophilia in any subject. Faecal specimens in 10 patients were negative for cysts, ova, and parasites. One of the 32 non-aspergillosis patients
Table 1 Number of positive results of Aspergillus fumigatus tests in the groups with and without allergic bronchopulmonary aspergillosis (ABPA)

\begin{tabular}{lll}
\hline & $\begin{array}{ll}A B P A \\
(n=33)\end{array}$ & $\begin{array}{l}\text { Non- } A B P A \\
(n=32)\end{array}$ \\
\hline Immediate skin test & 33 & 8 \\
Serum precipitins & 31 & 0 \\
Sputum culture & 24 & 3 \\
\hline
\end{tabular}

had the Churg-Strauss syndrome and one a $\overrightarrow{\overrightarrow{2}}$ hypereosinophilia like syndrome. Two patients had $\stackrel{f}{+}$ rheumatoid arthritis and two pernicious anaemia and $\overrightarrow{-}$ one had had sarcoidosis.

Fifty eight patients were asthmatic and seven non- $\frac{\overrightarrow{6}}{6}$ asthmatic. The asthmatic patients had been followed 0 up for longer than the non-asthmatic patients (median $14.5 \vee 2$ years; $p<0.05$ ). Six of the seven non- $z$ asthmatic patients did not have aspergillosis; in five of the seven patients episodes of aspergillosis were associated with systemic features (see below). In six patients pulmonary eosinophilia preceded the onset of asthma (interval 1-11, median 9 years).

Patients with allergic bronchopulmonary aspergillosis were more frequently asthmatic, atopic, and 0 male than those without aspergillosis and had lower blood eosinophil counts during episodes of pulmonary eosinophilia (table 3). The onset of asthma occurred at an earlier age in the group with aspergillosis (median $\stackrel{0}{\circ}$ $7.5 \vee 30.5$ years; $\mathrm{p}<0.01$ ) but age at the first documented episode of pulmonary eosinophilia was similar for the two groups (fig 1). The interval between onset of asthma and onset of pulmonary eosinophilia was therefore greater in the patients with allergic bronchopulmonary aspergillosis (median $19 v 11$ years; $p<0.05$ ). Patients with aspergillosis also had more episodes of pulmonary eosinophilia (median $5 v$ ? $2 ; p<0.01$ : fig 2) and a longer duration of follow up

Table 2 Significance of a positive skin test response to Aspergillus fumigatus in patients with pulmonary eosinophilia: comparison of clinical and investigative features with allergic bronchopulmonary aspergillosis (ABPA) and "definite" non-ABPA patients (see text)

\begin{tabular}{|c|c|c|c|}
\hline & \multirow[b]{2}{*}{$\begin{array}{l}A B P A \\
(n=33)\end{array}$} & \multicolumn{2}{|l|}{ Non- $A B P A$} \\
\hline & & $\begin{array}{l}\text { Positive skin response } \\
\text { alone }(n=8)\end{array}$ & $\begin{array}{l}\text { Definite non-ABPA} \\
(n=24)\end{array}$ \\
\hline $\begin{array}{l}\text { Aspergi!lus fumigatus } \\
\text { Skin test positive } \\
\text { Serum precipitin positive } \\
\text { Sputum culture positive } \\
\text { Asthmatic } \\
\text { Median (range) age of onset of asthma (y) } \\
\text { Median (range) age of onset of pulmonary eosinophilia }(y) \\
\text { Maximum blood eosinophil count during episodes } \times 10^{6} / 1 \\
\text { (group mean (SD)) } \\
\text { Number with systemic features during episodes } \\
\text { Fibrosis or bronchiectasis } \\
\text { Median (range) duration of follow up (y) }\end{array}$ & $\begin{array}{l}33 \\
31 \\
24 \\
32 \\
7 \cdot 5(1-61) \\
38(14-78) \\
\\
2290(3584) \\
4 \\
20 \\
17 \cdot 9(1-31 \cdot 5)\end{array}$ & $\begin{array}{l}8 \\
0 \\
0 \\
7 \\
29(2-49) \\
41(22-65) \\
4774(3681) \\
3 \\
3 \\
7(1-18)\end{array}$ & $\begin{array}{l}0 \\
0 \\
3 \\
19 \\
31(2-69) \\
39(13-67) \\
3109(2767) \\
9 \\
4 \\
12(1-29)\end{array}$ \\
\hline
\end{tabular}


Table 3 Clinical and investigative features of patients with pulmonary eosinophilia with and without allergic bronchopulmonary aspergillosis (ABPA)

\begin{tabular}{|c|c|c|c|}
\hline & $\begin{array}{l}A B P A \\
(n=33)\end{array}$ & $\begin{array}{l}\text { Non-ABPA } \\
(n=32)\end{array}$ & $p$ \\
\hline $\begin{array}{l}\text { Male : female } \\
\text { Atopic } \\
\text { Asthmatic } \\
\text { Median (range) age of onset of asthma (y) } \\
\text { Median (range) age of onset of pulmonary eosinophilia (y) } \\
\text { Number developing pulmonary eosinophilia before asthma } \\
\text { Maximum blood eosinophil count during episodes } \times 10^{6} / 1 \\
\text { (group mean (SD)) } \\
\text { Mean blood eosinophil count during episodes } \times 10^{6} / 1 \\
\text { (group mean (SD)) } \\
\text { Number with systemic features during episodes } \\
\text { Median (range) duration of follow up (y) }\end{array}$ & $\begin{array}{l}19: 14 \\
28 \\
32 \\
7 \cdot 5(1-61) \\
38(14-78) \\
2 \\
2290(3584) \\
1406(1287) \\
4 \\
17 \cdot 9(1-31 \cdot 5)\end{array}$ & $\begin{array}{l}8: 24 \\
17 \\
26 \\
30 \cdot 5(2-69) \\
40(13-67) \\
4 \\
3526(3045) \\
2858(2919) \\
12 \\
10 \cdot 1(1-29)\end{array}$ & $\begin{array}{l}<0.01 \\
<0.02 \\
<0.05 \\
<0.01 \\
\text { NS } \\
\text { NS } \\
<0.05 \\
<0.01 \\
<0.05 \\
<0.05\end{array}$ \\
\hline
\end{tabular}

(median $17.0 v 10.1$ years; $\mathrm{p}<0.05$ ). There was no seasonal variation in episodes of pulmonary eosinophilia in either group (fig 3). Radiological features consistent with bronchiectasis or fibrosis or both occurred more often in patients with allergic bronchopulmonary aspergillosis than in those without $(\mathrm{p}<0.005)($ table 4$)$.

The most common systemic features associated with episodes of pulmonary eosinophilia were night sweats,

\section{AGE AT FIRST PULMONARY EOSINOPHILIA IN ABPA AND NON-ABPA PATIENTS}
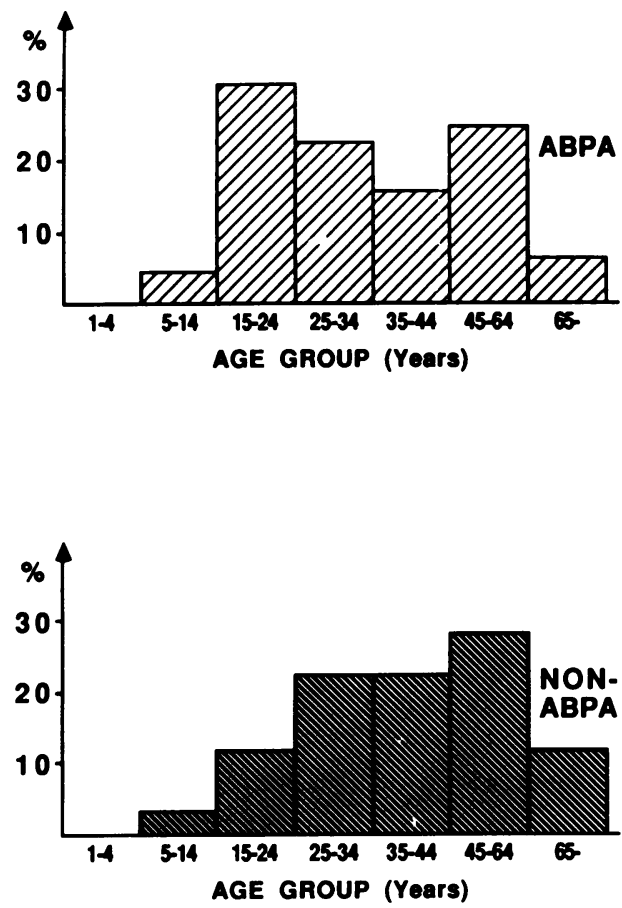

malaise, fever, rashes, and anaemia; they occurred more frequently in the group without allergic bronchopulmonary aspergillosis $\quad(44 \% \quad v \quad 9 \%$; $\mathrm{p}<0.005)$.

\section{Discussion}

Pulmonary eosinophilia was associated with allergic bronchopulmonary aspergillosis in 33 of the 65

\section{AGE AT ONSET OF ASTHMA IN ABPA AND NON-ABPA PATIENTS}
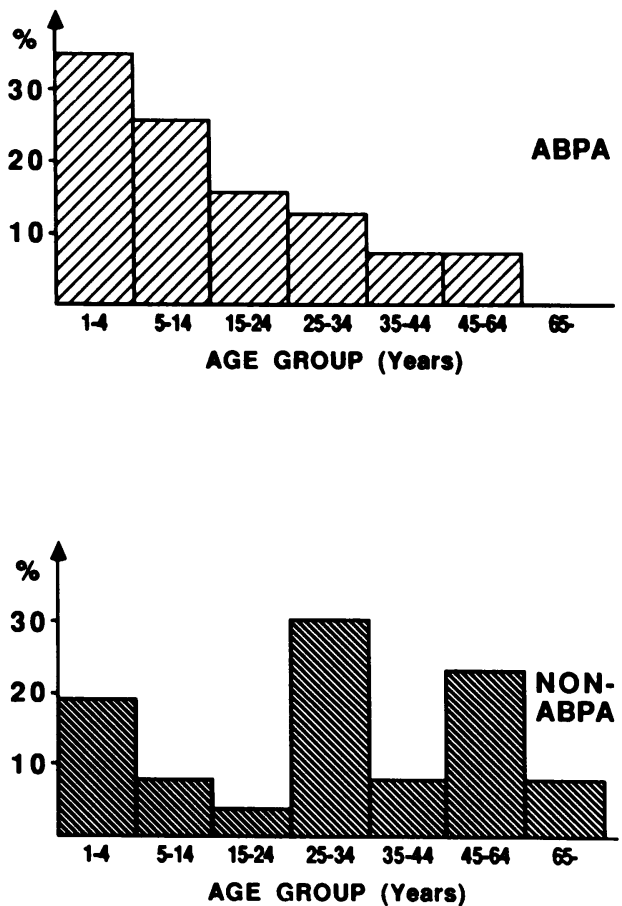

Fig 1 Age of onset of pulmonary eosinophilia and asthma in patients with and without allergic bronchopulmonary aspergillosis. 


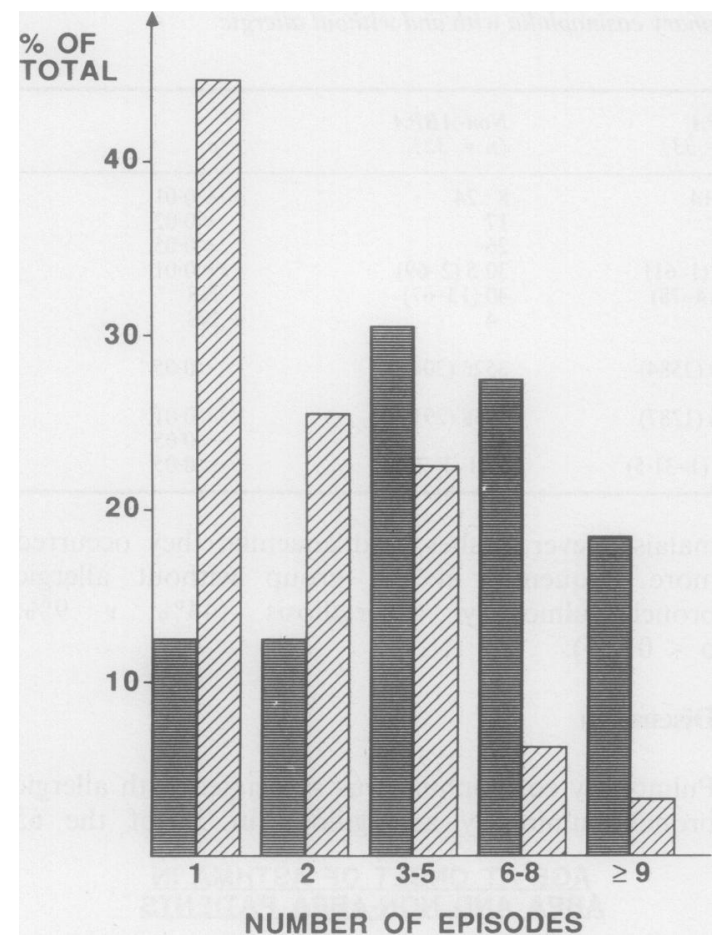

Fig 2 Number of episodes of pulmonary eosinophilia in

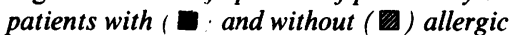
bronchopulmonary aspergillosis.

patients in this unselected series. Eighty per cent of cases of pulmonary eosinophilia were associated with allergic bronchopulmonary aspergillosis in the series of McCarthy and Pepys ${ }^{312}$ and $74 \%$ of 62 asthmatic patients in the study of Scadding. ${ }^{19}$ Middleton et al ${ }^{20}$ also studied 65 asthmatic patients with pulmonary eosinophilia, of whom 54 were fully investigated for allergic bronchopulmonary aspergillosis and 59\% were considered to have the disease. The differences between these figures probably reflects referral to secondary or tertiary referral centres, though a changing pattern of pulmonary eosinophilia during the last 15-20 years cannot be excluded. The increased use of oral and perhaps inhaled corticosteroid drugs during this period may have had an effect.

The diagnostic criteria used to define allergic bronchopulmonary aspergillosis remain controversial. In Britain the three essential criteria have generally been asthma, pulmonary eosinophilia, and a positive immediate skinprick test response to an extract of $A$ fumigatus. ${ }^{21-23}$ In the United States, however, serum precipitating antibodies to aspergillus antigens, a raised serum total IgE concentration, and when possible the appearance of proximal bronchiectasis on
No of episodes

of pulmonary eosinophilia

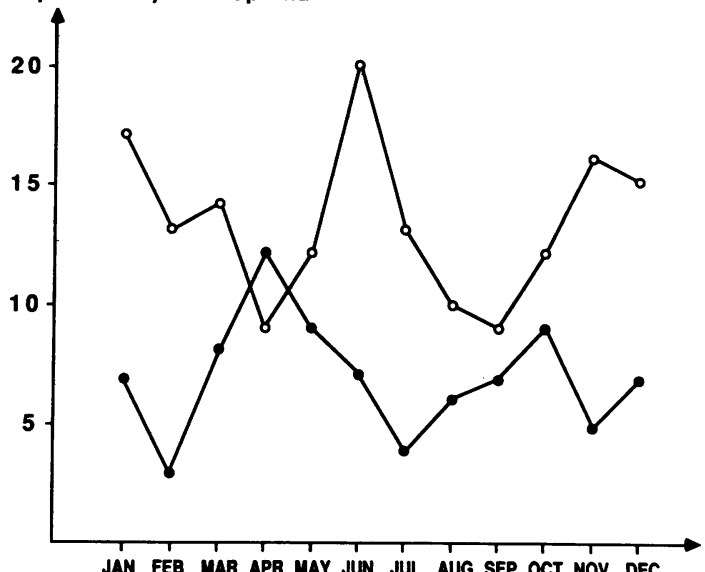

Fig 3 Monthly variation in number of episodes of bronchopulmonary eosinophilia in patients with ( $\mathrm{O})$ and without (•) allergic bronchopulmonary aspergillosis.

a bronchogram would also be required. ${ }^{24}$ In this study we chose to modify the UK criteria by insisting on the additional presence of either serum precipitating antibodies to $A$ fumigatus or $A$ fumigatus in the sputum as a positive skinprick test response alone may simply be a manifestation of atopy. Thirty three of the 65 patients fulfilled our criteria, and 41 met the UK criteria. The clinical and haematological features of the eight patients with pulmonary eosinophilia with a positive skin test response alone resembled the patients who did not have aspergillosis more closely than those with aspergillosis. In seven patients the positive skin test response may have been due to atopy. We suggest that the established UK criteria for the diagnosis of allergic bronchopulmonary aspergillosis are inadequate, and should be modified to include the presence of serum aspergillus precipitins.

Asthma appears not to be an essential feature for the diagnosis of allergic bronchopulmonary asper-

Table 4 Radiographic signs suggesting fibrosis and bronchiectasis in patients with pulmonary eosinophilia with and without allergic bronchopulmonary aspergillosis (ABPA)

\begin{tabular}{lll}
\hline & $\begin{array}{l}A B P A \\
(n=33)\end{array}$ & $\begin{array}{l}\text { Non- } A B P A \\
(n=32)\end{array}$ \\
\hline $\begin{array}{l}\text { Bronchogram proved } \\
\begin{array}{c}\text { Clinical features and chest radiographic } \\
\text { features suggesting fibrosis or } \\
\text { bronchiectasis }\end{array}\end{array}$ & 7 & 2 \\
$\begin{array}{l}\text { Chest radiographs suggesting fibrosis } \\
\text { or bronchiectasis }\end{array}$ & 11 & 2 \\
& $\frac{2}{20}$ & 3 \\
\hline
\end{tabular}

${ }^{*} \mathrm{p}<0.005$ 
gillosis. Une of the patients with aspergillosis in the present study did not have asthma, confirming other reports. ${ }^{3425}$ Glancy et al reported that three of their 11 non-asthmatic patients subsequently developed asthma two, four, and 10 years after the onset of pulmonary eosinophilia. In our series six patients developed asthma up to 11 years after the first recorded episode of pulmonary eosinophilia.

Most of our patients with allergic bronchopulmonary aspergillosis were male, in keeping with the findings of Scadding, ${ }^{19}$ but differing from the findings of other studies, where more patients were female. ${ }^{321}$ There is probably no clear male or female predominance overall.

Allergy to drugs or helminths was not identified in any of our patients. This unselected series also suggests that the Churg-Strauss and hypereosinophilic syndromes are uncommon causes of pulmonary eosinophilia, as they represented only $3 \%$ of our cases. Among 143 patients with pulmonary eosinophilia reported by McCarthy and Pepys, ${ }^{312}$ only two had evidence of polyarteritis nodosa, and Turner-Warwick and colleagues ${ }^{13}$ found no evidence of renal manifestations or necrotising vasculitis in 15 patients with cryptogenic pulmonary eosinophilia.

Comparison of the patients with and without allergic bronchopulmonary aspergillosis showed several differences. Fewer patients in the group without aspergillosis were asthmatic, possibly because the nonasthmatic patients had been followed up for a shorter period. The age of onset of pulmonary eosinophilia was similar in the two groups, but the age of onset of asthma was much lower in the group with aspergillosis, as might be expected because of the higher proportion of atopic patients in this group. The patients with aspergillosis had more documented episodes of pulmonary eosinophilia, as previously reported. ${ }^{3}$ The longer duration of follow up of the patients with aspergillosis, however, makes it difficult to be certain whether this is genuinely an increased frequency. Previous reports have shown that in the UK most episodes of pulmonary eosinophilia in patients with allergic bronchopulmonary aspergillosis occur in the autumn and winter, ${ }^{326}$ when aspergillus spore counts are at their highest. ${ }^{27} 28$ A similar relation between episodes of pulmonary eosinophilia and high atmospheric mould counts was noted in Chicago. ${ }^{29}$ The present study, however, showed no increase in the number of episodes of pulmonary eosinophilia during these months.

Pulmonary eosinophilia associated with allergic bronchopulmonary aspergillosis appears to be a distinct clinical syndrome, which once suspected is easy to diagnose. ${ }^{30}{ }^{31}$ Pulmonary eosinophilia without allergic bronchopulmonary aspergillosis differs clinically and may be associated with several different syndromes whose underlying pathogeneses remain unclear.

\section{References}

1 Crofton JW, Livingstone JL, Oswald NC, Roberts ATM. Pulmonary Eosinophilia. Thorax 1952;7:1-35.

2 Hinson KFW, Moon AJ, Plummer NS. Bronchopulmonary aspergillosis: a review and report of 8 new cases. Thorax 1952;7:317-33.

3 McCarthy DS, Pepys J. Allergic bronchopulmonary aspergillosis. Clinical immunology: (1) Clinical features. Clin Allergy 1971;1:261-86.

4 Glancy JJ, Elder JL, McAleer R. Allergic bronchopulmonary fungal disease without clinical asthma. Thorax 1981;36:345-9.

5 Cole P. Drug-induced lung disease. Drugs 1977;13: 422-44.

6 Churg J, Strauss L. Allergic granulomatosis, allergic angiitis, and periarteritis nodosa. Am J Pathol 1951;27:277-301.

7 Chumbley LC, Harrison EG, Deremee RA. Allergic granulomatosis and angiitis. Report and analysis of $\mathbf{3 0}$ cases. Mayo Clin Proc 1977;52:477-84.

8 Fauci AS, Harley JB, Roberts WC, Ferran VJ, Gralnick HR, Bjornson BH. The idiopathic hypereosinophilic syndrome: clinical, pathophysiologic and therapeutic considerations. Ann Intern Med 1982;97:78-92.

9 Spry CJF, Davies J, Tai PC, Olsen EGJ, Oakley CM, Goodwin JF. Clinical features of fifteen patients with the hypereosinophilic syndrome. $Q J \mathrm{Med} 1983 ; 52$ : $1-22$.

10 Neva FA, Ottesen FA. Current concepts in parasitology. Tropical (filarial) eosinophilia. $N$ Engl $J$ Med 1978;298:1129-31.

11 Liebow AA, Carrington CB. The eosinophilic pneumonias. Medicine (Baltimore) 1969;48:251-85.

12 McCarthy DS, Pepys J. Cryptogenic pulmonary eosinophilia. Clin Allergy 1973;3:339-51.

13 Turner-Warwick M, Assem ESK, Lockwood M. Cryptogenic pulmonary eosinophilia. Clin Allergy 1976;6:135-45.

14 Crofton JW, Douglas AC. Respiratory diseases, 3rd ed. Oxford: Blackwell, 1981:516-31.

15 Schatz M, Wasserman S, Patterson R. The eosinophil and the lung. Arch Intern Med 1982;142:1515-9.

16 Newman Taylor AJ. Pulmonary eosinophilia. In: Emerson P, ed. Thoracic medicine. London: Butterworths, 1981:777-84.

17 Lane DJ. Pulmonary eosinophilia. In: Weatherall DJ, Ledingham JGG, Warrell DA, eds. Oxford textbook of medicine. 2nd ed. Oxford: Oxford University Press, 1987;15:130-2.

18 Armitage P. Statistical methods in medical research. Oxford: Blackwell, 1971.

19 Scadding JG. Eosinophilic infiltrations of the lungs in asthmatics. Proc $R$ Soc Med 1971;64:381-92.

20 Middleton WG, Paterson IC, Grant IWB, Douglas AC. Asthmatic pulmonary eosinophilia: a review of 65 cases. Br J Dis Chest 1977;71:115-22.

21 Henderson AH. Allergic aspergillosis: review of 32 cases. Thorax 1968;23:501-12. 
22 Anon. Diagnosing allergic bronchopulmonary aspergillosis. Br Med J 1977;ii:1439-40.

23 Malo JL, Hawkins R, Pepys J. Studies in chronic allergic bronchopulmonary aspergillosis: 1. Clinical and physiological findings. Thorax 1977;32:254-61.

24 Rosenberg M, Patterson R, Mintzer R, Cooper BJ, Roberts M, Harris KE. Clinical and immunologic criteria for the diagnosis of allergic bronchopulmonary aspergillosis. Ann Intern Med 1977;86:405-14.

25 Berkin KE, Vernon DRH, Kerr JW. Lung collapse caused by allergic bronchopulmonary aspergillosis in non-asthmatic patients. $\mathrm{Br} \mathrm{Med} J$ 1982;285:552-3.

26 Safirstein BH, D'Souza MF, Simon G, Tai EH-C, Pepys J. Five-year follow-up of allergic bronchopulmonary aspergillosis. Am Rev Respir Dis 1973;108:450-9.
27 Hyde HA, Richards M, Williams DA. Allergy to mould spores in Britain. $\mathrm{Br}$ Med J 1956;i:886-90.

28 Noble WCN, Clayton YM. Fungi in the air of hospital wards. J Gen Microbiol 1963;32:397-402.

29 Radin RC, Greenberger PA, Patterson R, Ghory A. Mould counts and exacerbations of allergic bronchopulmonary aspergillosis. Clin Allergy 1983;13: 271-5.

30 Schuyler MR. Allergic bronchopulmonary aspergillosis. Clin Chest Med 1983;4:15-22.

31 Patterson R, Greenberger PA, Halwig JM, Liotta JL, Roberts M. Allergic bronchopulmonary aspergillosis. Natural history and classification of early disease by serologic and roentgenographic studies. Arch Intern Med 1986;146:916-8. 